\title{
LA ÚLTIMA VEZ QUE TE ESCRIBÍ. CONTEMPORIZANDO EL CONCEPTO DE DOCUMENTO EN LA CULTURA DE LA IMAGEN DOCUMENTAL: CORRESPONDENCIAS FÍLMICAS Y DIARIOS FILMADOS ${ }^{1}$
}

\section{THE LAST TIME THAT I WROTE YOU. UPDATING THE CONCEPT OF DOCUMENT IN THE CULTURE OF THE DOCUMENTARY IMAGE: \\ FILM CORRESPONDENCES AND DIARIES FILMED}

\author{
Vanesa FERNÁNDEZ GUERRA \\ Universidad Del País Vasco / Euskal Herriko Unibertsitatea \\ vanesa.fernandez@ehu.es \\ Estibaliz ALONSO RUIZ DE ERENTZUN \\ Universidad Del País Vasco / Euskal Herriko Unibertsitatea \\ estibaliz.alonso@ehu.es
}

Resumen: Las correspondencias fílmicas en cuanto documento resultan un objeto de especial interés semiótico como testigo, testimonio o prueba. El presente artículo se centra en el análisis de las correspondencias fílmicas Agosto sin ti (2014, Colectivo Audiovisual Las chicas de Pasaik). Imbricadas en el espacio de lo privado, las correspondencias fílmicas, los diarios de viaje o los autorretratos se asientan en lo íntimo, lo emocional y lo confesional, es por ello que enfatizaremos en la configuración de un determinado dispositivo en el que un tiempo, una voz (el "yo") y un espacio son emplazados por recursos narrativos.

Palabras clave: Documental. Diario filmado. Correspondencia fílmica. Agosto sin ti. Colectivo Audiovisual Las chicas de Pasaik.

Abstract: Film correspondences as soon as paper is an object of particular semiotic interest as a witness, testimony or evidence. This article focuses on the analysis of the film matches August without you (2014, audiovisual collective Pasaik Girls). Imbricate in private space, film correspondences, travel journals, or self-portraits settles in the intimate, emotional and confessional, this is why we will emphasize in the configuration

1 Este artículo se ha realizado dentro de las actividades del Grupo de Investigación GIU 13/21 (20132016), MAC (Mutaciones del Audiovisual Contemporáneo) de la Universidad del País Vasco / Euskal Herriko Unibertsitatea. 
of a particular device in which a time, a voice ("I") and a space are located by narrative resources.

Key Words: Documentary filmmaking. Filmed diary. Film correspondence. August without you. Collective Pasaik Girls.

Toda gran imagen simple es reveladora de un estado de alma Gastón Bachelard (La poética del espacio, 1957)

\section{A MODO DE INTRODUCCIÓN}

Vivimos en la época del postcine. Un panorama en el que el capitalismo postfordista, los dispositivos digitales y los nuevos modos de expresión audiovisuales han desplazado al cine de la posición que ocupaba en el siglo XX, y han multiplicado los medios, contextos y circunstancias en los que se produce la experiencia audiovisual contemporánea.

El dispositivo fílmico se reubica y, asílas cosas, podríamos hablar no tanto de el cine, sino de diversos cines que producen variadas y mutables formas de uso de lo cinematográfico que muchas veces lindan o incluso se imbrican con otras manifestaciones artísticas. Ante un universo audiovisual que se expande, el cine busca su sitio, un espacio cada vez más alejado de las salas cinematográficas y aún en proceso de creación y de emergencia. $Y$ no sería descabellado afirmar que en este exilio del cine contemporáneo mucho tienen que ver los cambios tecnológicos que han propiciado que las formas de hacer y de usar el cine estén en estos momentos en total reinvención de sí mismas.

Casi todo el mundo puede generar sus propias imágenes audiovisuales y ponerlas en circulación, filmando escenas de su vida cotidiana con un smart-phone, un dispositivo audiovisual hoy en día al alcance de cualquiera. Pero más allá de ese uso doméstico, la democratización y digitalización de la tecnología y la transformación de los modos de producción audiovisual han permitido la aparición de un cine de lo próximo, un cine íntimo y en primera persona que explora el ejercicio cinematográfico más allá de los modelos y códigos impuestos por la industria cinematográfica imperante y que practica un lenguaje propio buscando nuevas formas de mirar lo real y construir discursos sobre la realidad. De este cine trataremos en estas líneas, en particular de la correspondencia audiovisual que compone la pieza Agosto sin ti de María Elorza y Maider Fernández, o dicho de otro modo, del colectivo Las chicas de Pasaik.

En el caso concreto de Agosto sin ti, es gracias a las facilidades que ofrece la tecnología digital, que permite formas de trabajo alejadas de la parafernalia de las producciones convencionales y permite, al reducir el equipo al mínimo imprescindible, reproducir el 


\section{DIARIOS FILMADOS}

gesto del escritor de cartas y convertir la cámara casi literalmente en la caméra-stylo (cámara-pluma) de la que hablaba Alexande Astruc (1948).

Al sumergirnos en la acotación de lo que podría ser una película posmodernista, nos encontramos con un amplio abanico de concepciones en lo que se refiere a cine y postmodernidad. En ese espectro conviven desde la idea de que todo cine es intrínsecamente postmoderno hasta el planteamiento de que no hay películas posmodernas en sí sino que lo que sucede es que se realizan lecturas posmodernas de esas películas (Zavala, 2005). Esto es así por lo complejo de definir la postmodernidad en sí misma.

La postmodernidad hace alusión tanto a un periodo histórico como a la lógica cultural capitalista vigente, pero también a una nueva manera de reflexionar sobre lo social y lo cultural, y, por último, a un movimiento estético que surge como reacción a la tradición y el realismo moderno. En este caso, es este último concepto el que más nos interesa al referirnos a los trabajos que analizaremos más adelante, aunque deberemos, asimismo, prestar atención al contexto en que esas obras tienen lugar, ya que resultaría sesgado observar una película postmodernista sin atender, por ejemplo, el sistema económico en el que se instaura o las teorías sociales y culturales del periodo histórico en el que se crea.

Como apuntábamos en el párrafo anterior, bien podría decirse que todo cine es en realidad postmoderno, pues la unicidad, permanencia y trascendencia que se le otorga a cualquier manifestación artística, en el caso del cine es inevitablemente multiplicidad (múltiples copias, montaje de planos) y transitoriedad (exhibición puntual y experiencia cinematográfica efímera). Sin embargo, en la labor que nos ocupa, preferimos la perspectiva que adoptan ciertos teóricos, entre ellos Fredric Jameson, que define la postmodernidad como estilo, discurso y época, en cuanto que se asume como la lógica cultural del capitalismo tardío. Jameson reivindica la importancia que el concepto posmodernidad debería tener a la hora de analizar las producciones culturales contemporáneas (Jameson, 1991: 22), y es por ello, que, si bien los que aquí nos ocupan son trabajos marginales, en cuanto que se ubican en los márgenes, es decir, piezas audiovisuales que se desvían de los modos convencionales de la industria cinematográfica y de los gustos del público más generalista, estas obras comparten muchas de las características postmodernistas con esas otras películas del circuito más comercial. En palabras del propio Jameson:

Sin embargo, el posmodernismo es el campo de fuerza en que tipos muy diferentes de impulsos culturales (...) tienen que abrirse camino. Si no concebimos de manera general la existencia de una dominante cultural, nos vemos obligados a compartir el punto de vista que pretende que la historia actual es mera heterogeneidad, diferencia casual, coexistencia de innumerables fuerzas diversas cuya efectividad es indescifrable (Jameson, 1991: 21-22). 
En cualquier caso, entre las características a las que nos referimos están la intertextualidad y el reconocimiento de dichas alusiones por parte de la audiencia, espectadores con un cierto bagaje cinematográfico. Algo que Noëll Carroll (1998: 241) ha definido como "cine de alusión". Por otro lado, el cine postmoderno juega con la autorreferencialidad, a veces como parodia, pero también usando otras estrategias disruptivas que proponen una nueva relación con el espectador. En este sentido, como apunta Degli-Esposti (1998: 5), es Ilamativo también el interés postmoderno dedicado a evidenciar el acto de mirar; tanto con la presencia constante en pantalla de cámaras y monitores como con la explicitación de los mecanismos formales de captación de imagen, de forma que, en ocasiones, el mero hecho de comunicar suplanta el contenido mismo de dicha comunicación. A esto se une también la multiplicidad de estilos, que Connor (1997: 198) describe como una furiosa polifonía de voces descontextualizadas. En este caso, la fragmentación propia del estilo posmoderno sería un reflejo de la fragmentación de los propios sujetos. También la ironía es un rasgo común en el cine postmoderno. Ironía como cuestionamiento de la verdad y de la autenticidad, muchas veces como resignación ante la imposibilidad del cambio. Y por último, debemos hablar de la nostalgia y su exaltación, elementos que en el cine contemporáneo dan forma al desencanto de los hechos contemporáneos y que, según Jameson, elimina la sensación de origen histórico en cuanto que "la canibalización aleatoria de todos los estilos del pasado, el juego de la alusión estilística azarosa" (Jameson, 1996: 39). De todas estas características encontraremos ejemplos en la pieza que aquí se analizará.

\section{EL CARÁCTER INSTRUMENTAL DEL CONCEPTO DOCUMENTO (O ALGUNAS CUESTIONES DE ORDEN EPISTEMOLÓGICO)}

Antes de entrar en materia, en el propio análisis fílmico, quisiéramos exponer algunos postulados de los que partimos y que están directamente relacionados con el concepto de documento.

En primer lugar, nos gustaría reiterar aquí la afirmación que asevera que lo que se despliega ante los ojos del espectador no es la realidad, sino un fingimiento. Es decir, lo real es sin duda el proceso de captación de las imágenes. En el proceso de toma de esas imágenes ha habido cuerpos reales en un tiempo real ante una máquina que también es real, y todo esto ha sucedido en una duración temporal concreta. El registro mecánico en rollo de película o la grabación de datos en el soporte digital dan fe de ello. De manera que lo que está documentado es la relación entre cuerpo filmado y máquina filmante. $\mathrm{O}$ como expone Jean-Louis Comolli: 


\section{DIARIOS FILMADOS}

El cinematógrafo, como se ha dicho, combina los dos polos. La fotografía, no: ella los separa en el tiempo. Y el cine sí los combina en el tiempo: comparten una misma duración, la máquina y el espectador son sincrónicos en el momento de la proyección, como el cuerpo filmado y la máquina filmadora podían serlo en el momento de la toma de planos (Comolli, 2010: 108).

De manera que esta relación entre cuerpo filmado y cámara es dual: la máquina capta la luz y la duración que envuelven el cuerpo filmado, pero a su vez, el cuerpo filmado dirige a la máquina un mensaje, mensaje que, sin duda, también va dirigido a un espectador. Según Comolli (2010: 118):

en el otro polo, frente a la máquina, se sitúa por tanto la mirada de un sujeto, de un espectador, de un humano que ve desde el interior de su mundo mental, desde el interior de su residencia en el lenguaje. Un polo radicalmente subjetivo que se opone al que se considera objetivo... de eso que ha dado en llamarse, precisamente, el "objetivo" fotográfico o cinematográfico.

En el caso que nos ocupa, el de las correspondencias audiovisuales, podríamos hablar incluso de dos espectadores diferenciados: uno a quien se dirige la epístola concreta, otro a quien se dirige la correspondencia o pieza final. Por lo tanto, podríamos afirmar que no hay documento sin mirada. Del mismo modo que no hay cine sin espectador. O acudiendo de nuevo a Comolli, y citando al crítico Serge Daney, "aunque pueda proyectarse una película, no habrá cine si no hay espectadores en la sala" (Comolli, 2010: 108).

Así dispuestas las cosas, pareciera difícil hablar de documental en cuanto que siempre hay algo del sujeto que se mezcla en el proceso de creación de una secuencia audiovisual, sin embargo, podríamos afirmar que ninguna imagen cinematográfica puede identificarse con lo objetivo, auqnue sí podríamos imbricarla en lo documental, según confirma lo que lo que los teóricos han llamado la inscripción verdadera de la que hablábamos dos párrafos atrás.

¿Y de qué hablamos cuando hablamos de documental? Indudablemente, la pregunta no es baladí y cuestiones de este tipo llevan años formulándose entre no pocos intelectuales que han vislumbrado ciertas problemáticas con el nombre documental y han optado por (re)bautizarlo y sustituir el término, que en algunos casos se les antojaba arcaico, efímero y poco propicio. Así, las teorías que han surgido sobre las películas documentales son tan abundantes y dispares como autores y estudiosos sigue habiendo en la dedicación a su análisis y estudio. Desde que el propio John Grierson definiera el documental como the creative treatment of actuallity (1926), a propósito de Moana de 
Flaherty, que veía en el trabajo del joven cineasta las posibilidades que brindaba el cine para apoderarse de la realidad y reconvertirla en materia artística y expresiva, hasta nuestros días, casi todas las teorías al respecto nos llevan a la conclusión de que la distancia entre la ficción y la realidad, simplemente no existe (ni ha existido).

Por lo tanto, resulta difícil y no muy fructuoso pensar hoy en día en archiconocidas categorías, que a lo largo de los últimos años han sido ligadas a dicotomías como la de verdadero vs. falso, autenticidad vs. artificio o realidad vs. representación. La tangente entre el documental y la ficción y todas sus demarcaciones nos empujan, a la postre, a replantear concepciones básicas sobre el aspecto documental de la imagen cinematográfica que se ha entendido y se ha utilizado como si de una acta notarial se tratase $y$, en segundo lugar, reconsiderar el propio concepto de género al que el término documental se podría adherir.

Dicho de otro modo, no hay que olvidar, y el terreno de la semiosis lo asevera, que los signos icónicos de los que la imagen cinematográfica forma parte son "capaces de reproducir algunas de las condiciones de la percepción común, basándose en códigos perceptivos normales y seleccionando los estímulos que, con exclusión de otros, permiten construir una estructura perceptiva, que fundada en códigos de experiencia adquirida, tenga el mismo 'significado' que el de la experiencia real denotada por el significado icónico" (Eco, 1972: 72). Así dispuestas las cosas, "la imagen viene a convertirse así en un conjunto incluible en 'todo aquello que a partir de una convención aceptada previamente, pueda entenderse como alguna cosa que está en lugar de otra"' (Zunzunegui, 1995: 56). Por lo tanto, la imagen será un signo y producir signos "es situarse de entrada de lleno en el terreno de la posible mentira (...) La cámara no es, pues, lo que revela lo real, sino lo que construye una realidad nueva (la imagen y, más allá de ella, el texto fílmico) que no duplica el mundo sino que lo enriquece".

Abordar este fenómeno, pensamos, tiene importantes derivaciones ya que si reconocemos que toda película es un objeto que produce sentido, la corriente que entiende el cine documental como cine documento, como acta notarial de una realidad ha resultado de escasa rentabilidad hablando en términos conceptuales e ideológicos. Si todo film es una máquina de producción de sentido, se hace totalmente irrelevante cualquier distinción entre el cine de ficción y documental. Argumentación que nos lleva en primera instancia a admitir que "todo 'film narrativo' documenta una ficción, pero todo 'film documental' ficcionaliza una realidad preexistente"' (Zunzunegui, 1995: 56). J.L.Godard lleva insistiendo en esta cuestión desde hace medio siglo, argumentando que toda película es documental; cuando rodó À bout de souffle (1960), él mismo indicaba que era un documental sobre Belmondo y Jean Seberg. 


\section{DIARIOS FILMADOS}

Totalmente desarticulada, por lo tanto, la idea de que ninguna película documental refleja la supuesta realidad y verdad existente previamente, también tendríamos que ratificar que la verdad, ese

ejército móvil de metáforas, metonimias, antropomorfismos, en resumidas cuentas, una suma de relaciones humanas que han sido realzadas, extrapoladas, adornadas poética y retóricamente y que, después de un prolongado uso, a un pueblo le parecen fijas, canónicas, obligatorias: las verdades son ilusiones de las que se ha olvidado que lo son, metáforas que se han vuelto gastadas y sin fuerza sensible, monedas que han perdido su troquelado y no son ahora consideradas como monedas, sino como metal (Nietzsche, 1990: 11).

Huelga insistir de nuevo que el espectador no está ante la reproducción facsímil del mundo real; no es la realidad, la verdad, lo que se despliega ante sus desconcertados ojos sino un fingimiento supeditado al punto de vista del autor. Con respecto a esa realidad prefílmica, Pasolini argumentaba que"no se puede ver la realidad más que desde un solo ángulo visual: y este ángulo visual siempre es el de un sujeto que ve y oye" (Zunzunegui, 1995: 60).

Con todo ello, sostenemos que el carácter documental de toda película dilata y muta la imagen original (que no la realidad), el documento, en beneficio de la edificación de una nueva forma, de un sentido, "cuyo proceso de producción hará bascular definitivamente todo film del lado de su materialidad sígnica". Es decir, que asumimos y defendemos que si toda imagen es documental, todo film es ficción, teniendo en cuenta lo que representa (realidad fingida o desconocida) como por su forma de representarlo (su mutación creativa en imágenes). Retomando el diálogo teórico que apunta también en esta dirección, reforzamos la condición de objet filmique mal identifié que le reconoció Guy Gauthie (1995) al documental. Es por ello que "aceptar que la vocación del documental consiste en hacer una representación de la realidad y que esa representación debe ser objetiva: por esa puerta se cuelan todos los problemas. La aspiración de objetividad se enfrenta a todo tipo de escollos, suscitando cuestiones de manipulación, de intervención, de expresión, de subjetividad, y otras actitudes y estrategias prohibidas" (Weinrichter, 2004: 16). De ahí, que él también concluya afirmando que todo documental es ficción.

De modo que, como expresa Comolli (2010: 115), "el documento puede reconstruirse, inventarse, pasar a la ficción, escenificarse, y la película puede invertirse". Ya que, en cuanto que habla de un espectáculo a un espectador, el documento cinematográfico es autorreflexivo. "Lo que el cine pone en práctica y nos hace descubrir al mismo tiempo es la fragilidad del referente cuando queda atrapado en el juego de la película" (Comolli, 2010: 121) 


\section{EFECTOS DE SENTIDO: SOBRE LAS CORRESPONDENCIAS FILMICAS Y DIARIOS FILMADOS}

\subsection{LA VIDA COMO CINE}

Si nuestro interés radica en plantear la posibilidad de un tercer punto de vista más allá de la ontología y el lenguaje- desde el cual pueda pensarse la frontera entre documental y ficción, es necesario reconocer una serie de fenómenos que definen directamente la producción de documentales hoy. El panorama, sin embargo, es bastante amplio. Los cambios tecnológicos, las nuevas dinámicas de producción, los novedosos espacios de difusión y transmisión, el nacimiento de lenguajes audiovisuales inéditos, son factores extremadamente amplios que se relacionan, de una u otra manera, con la situación actual del documental. No es nuestro interés intentar abarcar cada uno de estos aspectos, sino más bien centrar nuestra atención en un fenómeno particular derivado del desarrollo de las tecnologías de la imagen ${ }^{1}$.

Diversos autores han señalado la aparición del vídeo, y más tarde del video digital, como uno de los acontecimientos más relevantes dentro del desarrollo del documental: la ampliación del ratio de grabación, la portabilidad de los equipos, la reducción de costos, las facilidades técnicas de grabación y edición, entre otros aspectos, componen lo que se ha denominado la "democratización" de la imagen característica de nuestra época.

Ahora bien, esta democratización de la imagen no implica solamente que la realización de documentales sea cada vez mayor por parte de aquellos interesados explícitamente en hacerlo -ya no solo documentalistas y realizadores de medios audiovisuales, sino también estudiantes de diversas áreas, profesionales de distintos campos, e incluso directores "aficionados» a través de cámaras caseras-, sino, sobre todo, una multiplicación de la posibilidad de registro de realidades particulares a través de la imagen. A todas las mejoras mencionadas anteriormente con respecto a la producción de documentales habría que sumar un aspecto que define a nuestra época más que a ninguna otra y que determina directamente la producción audiovisual contemporánea: la vida intima, diarios.

En medio de la amalgama que conforma el documental contemporáneo, que parece más que dispuesto a explorar sus propios límites, otras de las grandes transformaciones que podíamos apuntar son las retóricas poéticas, ensayísticas y subjetivas que habitan en él. Una metamorfosis o una evolución que se desencadena en lo que podríamos considerar como el giro subjetivo del documental, que ha marcado un punto de quiebre epistemológico y que cuestiona muchos de los preceptos que se han manifestado en la práctica y la teoría del documental. 


\section{DIARIOS FILMADOS}

No le faltaba razón a Serge Daney (1963) cuando señaló que la modernidad del cine llegó en el preciso momento en que el régimen de la imagen fílmica dejó de definirse como aquello que permite ver a través para pasar a convertirse en un artefacto de guerra contra el ilusionismo del cine clásico, enfatizando así, su dimensión de objeto construido, y por tanto, nada inocente. Si nos detenemos en su propuesta de pensar en la imagen, evidenciamos lo que en sus propios términos se define como una nueva escenografía de la mirada audiovisual, o lo que a efectos prácticos resulta lo mismo, una invitación a una visita guiada por el multiforme archipiélago que conforman unas imágenes en el que todas son intercambiables entre sí. O dicho de otro modo: visualidades de la subjetividad contemporánea.

En efecto, en esta época caracterizada por cierta prioridad de lo visual, siguiendo a Daney, y donde del mundo del arte hemos pasado al reino audiovisual, el devenir de la contemporaneidad cinematográfica se ha evidenciado y se ha abrigado en primera instancia en ese giro subjetivo hacia un yo en perpetua diseminación y deconstrucción. Así, el documental se presenta como la experiencia audiovisual de una subjetividad que no se reduce a una simple forma, sino que es expresada bajo el cobijo de una experiencia íntima y sentimental. Dicho de otro modo, el yo no se presenta como posible figura representativa, la experiencia de las imágenes transforman la propia mirada del personaje y del propio espectador. Se trata, por lo tanto, de esa necesidad y posibilidad de que todo se experimente como visual. De la posibilidad de que la subjetividad se disemine en su pluralidad visual y que las imágenes cinematográficas acontezcan como una experiencia más de todas estas formas visuales que inscriben los acontecimientos de nuestra contemporaneidad.

\subsection{EPÍSTOLAS DIGITALES}

Agosto sin ti es la forma que tienen dos jóvenes amigas de compartir un tiempo que, de hecho, no han pasado juntas: las vacaciones del mes de agosto. A través de un intercambio de breves vídeos en forma de diario Maider Fernández y María Elorza (el colectivo Las chicas de Pasaik) reconstruyen así su particular carta audiovisual "agosto $\sin \mathrm{ti}^{\prime \prime}$

Las cartas son cosa de dos. O de más personas, pero empiezan siempre con forma de espejo: yo te escribo, tú me escribes, nosotros nos escribimos. Correspondencia viene de co-responder; co-responder viene de atender, de escuchar, de tocar; dicho de dos o más personas; comunicarse por escrito, recíprocamente. 
En las citadas correspondencias, el documento se plantea como elemento central ya que, como las propias autoras afirman, el término correspondencia viene de coresponder, es decir, es un acto recíproco que se puede llegar a enunciar de disímiles modos (tanto visualmente, sonoramente o audiovisualmente).

Que una pareja de jóvenes directoras tengan el impulso fílmico de corresponderse fílmicamente solamente se puede entender términos estrictamente digitales:

Nunca podrás hacer Lawrence de Arabia. Ni Andrei Rublev. Ni Vértigo. Pero poseemos los medios (y esto es algo nuevo) para una nueva forma de hacer cine, íntima y solitaria. El proceso de hacer películas en comunión con uno mismo, la forma en que trabaja un pintor o un escritor, ahora no solamente tiene que ser experimental. El concepto de mi camarada Alexandre Astruc de la cámara como estilográfica era sólo una metáfora. En su época, el producto cinematográfico más humilde necesitaba un laboratorio, una sala de montaje y mucho dinero... Ahora, un joven cineasta necesita sólo una idea y un pequeño equipo para probarse a símismo².

Así de contundente se mostraba Chris Marker, siempre resbaladizo y parco en sus declaraciones, en una de las pocas entrevistas que concedió cuando se refería al cineasta del futuro.

Y, aunque no se trata de hacer aquí ninguna exaltación a ultranza de lo técnico, ni de defender la idea de que los cambios tecnológicos son la solución a todos los problemas del arte ni los otros muchos que encontramos en el mundo contemporáneo, sí es cierto que las tecnologías y sus potencialidades favorecen que jóvenes como el colectivo Las chicas de Pasaik, con un presupuesto mínimo, sean capaces de adquirir y manejar dos handycam medio-profesionales y que con un software de fácil uso instalado en un portátil lleguen a conseguir un producto que supera los estándares mínimos de calidad. Se demuestra así cómo la innovación tecnológica permite adentrar a la imagen a puntos fascinantes, y que a través del tratamiento de la imagen, se llegan a efectos pocas veces producidos.

Estamos pues ante un territorio en continua transformación, en el que lo digital marca un antes y un después en diferentes niveles y el cine contemporáneo no se limita a observarlo sino que es consciente de que se le abren horizontes inexplorados. Intentaremos aquí señalar un territorio en continua transformación gracias en parte a las nuevas tecnologías, intentando apuntar algunas cuestiones que nos parecen decisivas.

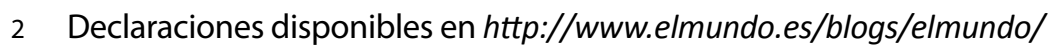
elvientosopladondequiere/2012/07/31/liberaciones.htm/ [23/10/ 2015]. 


\section{DIARIOS FILMADOS}

En el preciso momento en el que parecen coincidir diversas teorías sobre el fin del arte, la muerte del autor, e, incluso, sobre el fin de la historia, es donde lo digital irrumpe como tecnología perturbadora provocando alteraciones de diferentes envergaduras. Así pues, en esta era de la información (Castells), era digital (Gates) o era postmedia (Guattari, Brea), lo digital marca un antes y un después en diferentes niveles y el cine contemporáneo no se limita a observarlo, ya que es consciente que ya no solamente le concierne la imagen digital, sino también la expansión de los flujos globales de información y conocimiento y la propagación de las redes informáticas.

Asimismo, la tecnología digital y su facilidad de uso y acceso, ha permitido que dentro del sistema institucional, algunos cineastas exploren los límites del relato audiovisual, a través de la práctica de la (auto)filmación. Junto con la reinvención de los mecanismos de puesta en escena y aprovechando las posibilidades de experimentación estética y formal de los soportes audiovisuales, la autobiografía, el autorretrato, la autorreferencialidad como escritura fílmica y escritura de la propia vida, consiguen que el público reflexione desde una postura mucho más activa sobre los propios engranajes que hacen posible la película, y del mismo modo, anima al propio espectador a preguntarse sobre su condición en el mundo. Estas narrativas del yo, logran romper con lo uniforme y estereotipado, transitan por espacios personales y domésticos, logrando una especie de espectacularización de lo cotidiano.

Es más, desde ese yo, y a través de articulaciones muy vinculadas al cine experimental, se consigue que el público reflexione desde una postura mucho más activa sobre los propios engranajes que hacen posible la película, y del mismo modo, y siguiendo de nuevo esa mirada del yo, se persigue una segunda reflexión; la del propio espectador sobre su condición en el mundo, la crisis de la identidad, muy característica en la contemporaneidad, y en este caso también, la del propio colectivo sobre su ubicación y razón de ser, en contraposición a ciertos síntomas del individualismo narcisista que impera en el panorama audiovisual.

Este posicionamiento del yo, esa búsqueda personal de la mirada conformaría una nueva modalidad de discurso, que surge de manera natural en la década de los noventa, cuando irrumpe con fuerza un documental con fuertes marcas de reflexividad, para hablar desde la propia experiencia filmada. El documental pasó de ser una cámara-puño a una cámara-espejo, para posteriormente transformarse en una cámara-lápiz, o lo que términos más precisos, podríamos consideras en un sujeto-cámara. Estas narrativas del yo, que precisamente logran romper con lo uniforme y esteriotipado, transitan por espacios personales y domésticos, logrando una especie de espectacularización de lo cotidiano. 
Este análisis nos acercará a ese cine autobiográfico en forma de correspondencias para explorar su relación con ese objeto heterogéneo y poliédrico que es el documento y las múltiples formas de contar el tiempo presente.

Tras el título de la pieza, el sonido de unos pájaros da paso al primer intertítulo que establece el punto de partida de la pieza, y se lee en la pantalla:"Querida Maider: nuestros días aquí son ociosos y lentos". Así comienza, de la forma más canónica, usando el recurso epistolar, "Querida Maider", esta correspondencia, la de dos amigas que se "escriben" audiovisualmente durante el verano.

Correspondencia que será contraste de estilos y discursos y en la que veremos muchos de los rasgos que apuntábamos anteriormente. En esta primera parte, los "días ociosos y lentos" toman forma en una mujer que escribe mientras vigila la comida que se cocina lentamente. Un intertítulo nos confirmará que se trata de la madre de una de las autoras, "melancólica" y taciturna. Una mujer que recita con lenta cadencia en italiano, mientras en imagen vemos que comparte baño con quienes parecen ser de su familia. Cuando la voz cesa, no hay más sonido que el de las salpicaduras del agua y las olas que rompen en la playa. María Elorza coloca a su madre en un paisaje solitario de costa, en el que el silencio y la propia nos remiten, de alguna manera, al neorrealismo italiano. La figura de la madre parece ser en cierta manera el alter ego de su hija, una de las autoras, que más adelante se autodefinirá a sí misma a través del paisaje con palabras como "silencioso, íntimo, un poco melancólico quizá".

Los planos de esta primera epístola son estáticos o de movimientos controlados y suaves, lo que provoca en el espectador una sensación de densidad y tristeza. A pesar de su aparente simplicidad, la narrativa y los sólidos encuadres de esta parte van más allá de lo contemplativo y lo observacional y parecen querer transmitir el peso del tiempo. Algo que poco tiene que ver con lo que será la contestación de Maider Fernández a esta primera "carta audiovisual".

En contraposición, Fernández no escribe sobre la pantalla sino que utiliza la voz en off para con-responder a su compañera María. Es su contestación un pastiche de imágenes aparentemente inconexas entre sí, llenas de movimiento interno y movimientos de plano, usados a veces incluso de manera aberrante. Son imágenes nacidas, como ella misma dice "de un impulso sin ningún tipo de premeditación, "fragmentos" de su verano en Donostia-San Sebastián que darán paso a través del sonido del mar a Sicilia, donde Elorza nos introduce en una conversación de sobremesa y donde la nostalgia sigue siendo palpable. A través de planos muy cortos, mucho de ellos de detalle, también "fragmentos", pero de una índole muy diferente de los de Fernández, se nos introduce un grupo de amigos culto que, en su madurez, habla de temas sin aparente trascendencia, pero con un cierto poso de desencanto. Se habla del pasado, haciendo referencia al comienzo de la Iliada, al estudio durante su juventud de los idiomas bálticos... Sigue 


\section{DIARIOS FILMADOS}

siendo un estilo distanciado, limpio, sobrio, mirando a la imagen desde fuera de la propia imagen, aunque por un momento la voz de la autora se escucha en pantalla: “¿Yoko Ono?". Es la primera vez que oímos la voz de Elorza, frente a la voz de Fernández, a quién hemos oído ya en offe incluso hemos visto cantando en imagen.

Esta alternancia de tono, estética y recursos formales será la tónica predominante en la pieza. En las partes de Elorza, todas en blanco y negro, se observará una constante estilización formal e incluso un cierto distanciamiento sugerido por la propia distancia física de grabación. Las "epístolas" de Fernández serán en color, en ellas la cámara de acercará más a los objetos (casi siempre sujetos) y los encuadres parecerán menos estudiados y la posición de la autor más cercana a lo que filma.

\subsection{FORMAS DE EXPERIENCIA}

Cineasta de cuerpos, posturas y abrazos, de soledades, desplazamientos, errancias y ruinas vivas, de relatos y encuentros apenas esbozados, Akerman buscó, en palabras de Dana Linssen (2012):

images that represent nothing, and mean nothing else (except perhaps themselves - and even this is difficult enough) while she focuses her camera on observing the minutiae of women's lives, is expressed in the first instance by her style: distant, clean, sober, looking at the image outside of the image. Rootless, detached images. Images in the Diaspora. Is it possible to return home, to where the image can exist, outside of the commandment? Is such an image even possible?

Al igual que Akerman, las correspondencias aquí tratadas también nos embullen a una reflexión sobre el de la propia forma videográfica. Es decir, en cuanto a técnica relativamente accesible, emerge también una oportunidad donde una producción de obras notoriamente narcisistas e individualistas tienen cabida, lo que en algunos contextos lo denominan cine de autor y lo que nosotros hemos considerado como una nueva propensión o fenómeno que va más allá de una simple tendencia o hype: el cine del yo o el giro subjetivo del documental.

A través de nuevas formas o soportes, comunicando entre sí ideas hasta ahora incomunicables, y el propio YO creando nuevas formas de comunicarse consigo mismo, de auto-presentarse y auto-interpretarse. Es en este alto grado de auto-reflexividad que se muestra la postmodernidad, la 'percepción subjetiva del yo individual'. Las posibilidades creativas de esta situación crecen 
considerablemente si pensamos en la diversidad de los procesos operativos mentales que vendrían de la simple idea de auto-comunicarnos por vía de la imagen tan sensorialmente presente en nuestra vivencia (Manuela Penafría \& Gonzalo Madail, en línea).

La distancia y el tiempo van calando en la correspondencia y deriva en un tono nostálgico probablemente como reflejo del tiempo que les ha tocado vivir a las jóvenes directoras. Ya en el final se produce el encuentro físico entre las dos cineastas que en tono jocoso se dan la bienvenida y se despiden de ese "agosto sin ti". En resumidas cuentas, y tal y como Gilles Lipovetsky junto a Jean Serroy (2009: 15) apuntan, desde la década de los 80 nos hallamos en una nueva era del cine: una era hipermoderna que es capaz de generar "un cine global, fragmentado, de identidad plural y multiculturalista".

Esta era, la era de la pantalla global, el nuevo siglo conformado por la pantalla omnipresente, multiforme y multimediática. La todopantalla ha trastocado todas las dimensiones del universo cinematográfico: la creación, la producción, la promoción, la distribución y el consumo y también a la estética filmica. En resumidas cuentas, este nuevo cine se caracteriza por tres tipos de imagen: la imagen-exceso (el bombardeo visual que se concreta en la estética), la imagen-multiplejidad (la nueva complejidad tanto en el contenido como en la forma del cine) y, por último, la imagen-distancia (que implica una actitud cognitiva del espectador y contempla el cine dentro del cine) (2009: 15). Se trata de abordar la economía general del cine de la nueva época, "reconociendo en él una capacidad transformadora de lo imaginario cultural global. Una economía del cine a la vez cultural y socioestética, transpolítica y antropológica" (2009: 15).

\section{CONCLUSIÓN. LOS VERANOS SE OLVIDARÁN...}

¿Qué nos enseña la práctica cinematográfica sobre la cuestión del "documento"? Pues que no hay documento sin mirada. Del mismo modo que no hay cine sin espectador.

Esta escritura del yo encuentra acomodo y se ajusta perfectamente a través del cineensayo, una forma que sólo cristalizaría a partir de la década de los noventa, cuando el documental experimentó verdaderamente un auténtico giro subjetivo que iba a marcar su futuro. "El sujeto del nuevo documental subjetivo no es simplemente una traslación ectoplásmica del autor invisible de las novelas o del cine de ficción, una autor que no era menos transparente en los documentales clásicos. En todo caso, si a alguna figura puede compararse, por su presencia y centralidad, es a la de los autores de los diarios personales, de las autobiografías, de los ensayos, géneros todos ellos marginales hasta hace bien poco en el panorama literario" (Catalá, 2010: 43). 


\section{DIARIOS FILMADOS}

Las tres condiciones que posteriormente J.M. Català (2010: 43) menciona, presencia central, visibilidad corpórea y capacidad discursiva son las que se dan en los sujetos de los nuevos documentales subjetivos. "A ello debe añadirse una voluntad exploratoria y autorreflexiva que proviene de las derivaciones que el documental clásico empezó a experimentar a partir de mediados de los años cincuenta del pasado siglo, justo cuando la televisión empezaba a incorporar también, aunque menos trascendentalmente, la figura del enunciador en el campo visible del enunciado".

Dicha reflexividad se plasma a través de actitudes participativas e interactivas que el realizador muestra con los personajes, y por otro lado, a través del metacomentario o metatexto del que el director se aprovecha para construir otra forma de discurso: "podría describirse como un equivalente al ensayo en tanto que género literario y de reflexión intelectual (...) Un conjunto de obras que, a veces partiendo de, o citando, unos textos de la más amplia gama (literarios, filosóficos, estéticos, historiográficos... o mismamente audiovisuales), y entrecruzando diversos discursos propios y ajenos, disuelven los bordes entre los géneros supuestamente elementales (la narrativa, el documental, lo experimental, etc.) y se constituyen a menudo en collages textuales y, por extensión, audiovisuales" (Català, 2010: 43).

Así, y a pesar de que la heterogeneidad de este tipo de reflexividades en el documental impide una clara delimitación de la misma, es patente que lo que se intenta buscar es hacer consciente y partícipe al espectador de todo el proceso de producción. Pero ante todo, aseveramos que reflexividad supone pensar sobre el pensar, mirar cómo miramos y filmar sobre el filmar. Un trabajo de reflexión cinematográfica, en definitiva, y más específicamente, de reflexión articulada a través de las imágenes y el sonido. Una introspección que gira en torno al propio dispositivo, es decir, se cuestiona la naturaleza de la imagen fílmica, cuestionando por ende, la aparente veracidad de la representación documental y su supuesta ficcionalidad.

Por último, no se nos debe pasar por alto una última cuestión. Este giro subjetivo, y también gracias a la forma de cine-ensayo, permite que asistamos en los últimos tiempos y nos habituemos, a que los cineastas ya no solamente hacen películas, sino que reflexionan sobre ellas (la imagen que piensa godardiana). Así, práctica y reflexión teórica se fusionan y son bastantes cineastas los que deciden acompañar sus trabajos con textos y reflexiones ad hoc. 


\section{REFERENCIAS BIBLIOGRÁFICAS}

ASTRUCT, A. (1948). "Nacimiento de una nueva vanguardia: la 'caméra-stylo". Originalmente publicado en L'Écran Français 144, 30 de marzo de 1948. En Joaquim Romaguera i Ramió, y Thevenet Homero Alsina (eds.). Textos y manifiestos del cine. Estética. Escuelas. Movimiento. Disciplinas. Innovaciones. Madrid: Cátedra, 2007.

CATALÀ, J.M. (2010). “Nuevas vías del documental". En .DOC. El documentalismo en el siglo XXI, Antonio Weinrichter (ed.), 33-52. San Sebastián: Festival Internacional de Cine de DonostiaSan Sebastián.

CARROLL, N. (1998). Interpreting the moving image. Cambridge: Cambridge University Press.

COMOLLI, J. L. (2010). “Documento y espectáculo". En Arte, ciencia y espectáculo. Un panorama crítico, 76-89. Buenos Aires: Espacio Fundación Telefónica.

CONNOR, S. (1997). Postmodernist Culture. An Introduction to Theories of the Contemporary. Oxford: Blackwell.

DANEY, S. (1983). La Rampe, Cahier critique 1970-1982. Paris: Gallimard (Collection Cahiers du Cinema).

DEGLI-ESPOSTI, C. (ed.) (1998). Postmodernism in the Cinema. Oxford / Nueva York: Berghahn Books.

HUYSSEN, A. (1995). Twilight Memories: Marking Time in a Culture of Amnesia. Nueva York: Routledge.

JAMESON, F. (1996). Teoría de la posmodernidad. Madrid:Trotta.

LIPOVETSKY G. y SERROY, J (2009). La pantalla global, Cultura mediática y cine en la era hipermoderna. Barcelona: Anagrama.

LINSSEN, D. (2012). "A letter". Lola Journal 2, en línea: http://lolajournal.com/letter_23.html [23/10/2015]. Publicado originalmente en Retrospektive Chantal Akerman, a publication of the Viennale/ Austrian Filmmuseum, Astrid Ofner, Stefan Flach \& Claudia Siefen (eds.). Viena: Biennale and the Austrian Film Museum.

PENAFRÍA, M. \& MADAIL, G. (en línea). “Nuevos lenguajes audiovisuales. El documentalismo como género de experimentación". Docúpolis Magazine Tercer Ojo 2. Disponible en http:// www.docupolis.org/numero2/afondo.htm [23/10/2015].

ZAVALA, L. (2005). "Cine clásico, moderno y posmoderno". Razón y Palabra 46. Disponible en http://www.razonypalabra.org.mx/anteriores/n46/Izavala.html [23/10/2015].

ZUNZUNEGUI, S. (1995). "Imagen, documental, ficción”. Revista de Ciencias de la Información (UCM) 2, 53-62. 